\title{
HIGH BODY FAT PERCENTAGE AMONG ADULT WOMEN IN MALAYSIA: THE ROLE OF LIFESTYLE
}

S. M. Johari ${ }^{1}$, N. J. Nordin ${ }^{1, *}$, M. A. Sahar ${ }^{1}$, A. H. Sulaiman ${ }^{1}$, S. Shahar ${ }^{2}$, N. I. M. F. Teng ${ }^{3}$, N. A. Amin $^{4}$ and A. S. M. Saudi ${ }^{4}$

${ }^{1}$ Faculty of Medicine and Health Sciences, UniversitiSains Islam Malaysia, 55100 Kuala Lumpur, Malaysia

${ }^{2}$ Faculty of Health Sciences, UniversitiKebangsaan Malaysia, 50300 Kuala Lumpur,Malaysia

${ }^{3}$ Faculty of Health Sciences,UniversitiTeknologi MARA, 42300 PuncakAlam, Selangor, Malaysia

${ }^{4}$ Institute of Medical Science Technology (MESTECH), Universiti Kuala Lumpur, 43000 Kajang, Selangor, Malaysia

Published online: 05 October 2017

\begin{abstract}
Body fat percentage is regarded as an important measurement for diagnosis of obesity. The aim of this study is to determine the association of high body fat percentage (BF\%) and lifestyle among adult women. The study was conducted on 327 women, aged 40-59 years, recruited during a health screening program. Data on socio-demography, dietary intake and physical activity were collected through validated questionnaires. $\mathrm{BF} \%$ was measured using InBody 270 Body Impedance analyzer machine. Association between lifestyle factors and body fat percentage were investigated using multiple linear regression, adjusted for age and body mass index (BMI). Intake of protein, calcium and physical activity on household intensity were the predictors of high $\mathrm{BF} \%$.
\end{abstract}

Author Correspondence, e-mail: njuliana@usim.edu.my

doi: http://dx.doi.org/10.4314/jfas.v9i4s.52 
Keywords: body fat; obesity; women; Malaysia; lifestyle.

\section{INTRODUCTION}

\subsection{Body Mass Index (BMI) and Body Fat \% (BF\%)}

Obesity is becoming more prevalent worldwide. It is defined as abnormal or excessive fat accumulation that may impair health. Due to its simplicity and association with diseases, Body Mass Index (BMI) is the most commonly used method to diagnose obesity at the population level [1]. However, the recommended BMI cut-off values for overweight and obesity have been criticised due to their inconsistent relationship with body fat percentage $(\mathrm{BF} \%)$ [2-4]. Moreover, it is also limited to discriminate between fat and lean mass [5]. Given these findings, there may be a variation in BF\% for the same BMI range among people in a population or between individuals [6]. Thus, $\mathrm{BF} \%$ is regarded as one of the most important measurement for diagnosis of obesity whereby excess BF\% has been shown to be associated with metabolic dysregulation regardless of body weight [7].

\subsection{Obesity and Overweight in Malaysia}

Based on the recent National Health Morbidity Survey [8], by using the World Health Organization [9] classification, the prevalence of overweight and obesity in Malaysia were $33.4 \%$ and $17.7 \%$ respectively. More precisely, the prevalence of obesity was significantly higher among women $(20.6 \%)$ than men (15.0\%). Moreover, hypercholesterolemia was reported as significantly more prevalent among women $(52.2 \%)$ than men $(43.5 \%)$. The prevalence of diabetes mellitus (DM), although not significant was also higher among adult women $(18.3 \%)$ as compared to men $(16.7 \%)$.

\subsection{Health Related Outcomes among Obese and Overweight Women Adult}

Having excess body fat and being overweight or obese negatively impacts health in many ways and can account for many diseases. Specifically, among women, the risk of DM increases with a more central or visceral distribution of body fat [10]. Other than that, abdominal obesity may be harmful in women as waist circumference is an independent risk factor for developing coronary artery disease (CAD). Moreover, morbidly obese women had an odd ratio (OR) of 2.7 for $\mathrm{CAD}$ and 5.4 for hypertension which are higher than men [11].

Obesity is frequently associated with disturbances in menstrual cycle [12]. As the impact of 
this condition, it can affect fertility. One of the problem related to this is polycystic ovarian syndrome (PCOS) and this can be attributed to multiple endocrine mechanisms [13]. It can also cause pregnancy complications due to elevated risks of antepartum complications and mechanical difficulties with delivery. The complications include pregnancy-induced hypertension, preeclampsia, gestational diabetes, caesarean section and neonatal death [10].

Evidence of cancer risk among obesity and overweight women is also raising, namely breast, ovarian, cervical and endometrial cancer. Obese women with cancer may have decreased survival because of co-morbid illness or poorer response to treatment. They may also have increased surgical and possibly radiation complications [14].

\subsection{Lifestyle Factors and High BF\%}

A healthy lifestyle is a crucial factor for the prevention of having excess body fat. The percentage of energy from dietary fat is believed to be an important determinant of body fat accumulation. Theoretically, diet composition could affect body fat contents through metabolism of fat calories and that will cause a tendency to partition the calories in adipose tissue [15]. Other than that, higher calorie intake will also involve digesting and disposing of fatty acids, carbohydrate or protein as storage as fat or glycogen in the body [16]. In general, the contributions of dietary composition and body fat must consider the metabolic state of a person. Thus, the overall energy balance will have significant effect on net energy storage resulting from the ingestion of food [15].

Other than dietary intake, physical activity is well-known to be a modifiable factor for fatness issues and its related health risks. It has been suggested that physical activity can reduce the risk of various diseases that is associated with overweight, obese or excess body fat [17]. Moreover, physical activity may provide a low-risk method of preventing weight gain and maintenance of weight loss among overweight and obese women [18].

\section{METHODOLOGY}

This cross-sectional study was carried out from 2014 until 2016. Ethical approval was obtained from Ethical Committee of Islamic Science University of Malaysia (USIM) and informed consent was obtained from all subjects. 


\subsection{Subjects}

Subjects involved in this study were volunteers consist of Malay, Chinese and Indian adult women aged 40-59 years, recruited during a health screening program at multiple designated community centres. All subjects were able to communicate and residing in an urban area of central Malaysia. Exclusion criteria included those who have mental disorders, concomitant diseases (i.e. dialysis, cancer and stroke) and being handicapped.

\subsection{Demographic, Anthropometry, Dietary Intake and Physical Activity}

All subjects were recruited at multiple designated community centres for screening. Interview sessions were carried out based on a pretested questionnaire to collect data on socio-demography (age, gender, education status and marital status), dietary intake and physical activity. The face-to-face interview sessions were conducted by trained fieldworkers. More specifically, dietary intake was assessed using diet history questionnaire (DHQ) [44]. Nutritionist-Pro software (Axxya Systems) was used to estimate energy and nutrient intake by converting household measurement serving size into estimated food weight in gram. Physical activity level was assessed using Short Questionnaire to Assess Health-Enhancing Physical Activity (SQUASH) [45].

Anthropometry measurements including body height, weight and body fat percentage (BF\%) were measured using calibrated InBody 270 Body Impedance Analyzer machine to the nearest $0.1 \mathrm{~cm}, \mathrm{~kg}$ and \%. Body mass index (BMI) was calculated as body weight/standing height $\left(\mathrm{kg} / \mathrm{m}^{2}\right)$. BF\% was classified according to cut off points by [19]. Based on this definition, a subject is classified as having high adiposity if the $\mathrm{BF} \%$ is more than $33 \%$.

\subsection{Statistical Analysis}

Statistical Package for Social Sciences (SPSS) software version 21.0 was employed for all statistical analyses. Descriptive analysis was carried out on socio-demography, anthropometry, dietary intake and physical activity data. Prevalence of obesity, overweight and high BF\% were presented in percentage. Multiple linear regression (Stepwise Method) analysis was employed to determine the relative predictors of high $\mathrm{BF} \%$ at $\mathrm{p}<0.05$.

\section{RESULTS AND DISCUSSION}

In the present study, subjects were aged $40-59$ years (mean $50.4 \pm 5.6$ years) consist of mostly 
Malays (70.0\%), followed by Chinese (17.4\%), Indian (12.2\%) and "others" $(0.3 \%)$ (Table 1$)$. There were no significant different in education level and working status among the normal and high $\mathrm{BF} \%$ subjects. Prevalence of high $\mathrm{BF} \%$ was $72.8 \%$. Generally, the mean of high $\mathrm{BF} \%$ among this population was $38.2 \pm 8.2 \%$. Specifically, the mean for normal group was $28.0 \pm$ 4.1\%. While among high BF\% group, the mean was $41.9 \pm 5.7 \%(\mathrm{p}<0.001)$.

Overall, for dietary data, only carbohydrate intake showed significant difference between the two groups where carbohydrate intake was higher among normal group $(180.7 \pm 49.8 \mathrm{~g} / \mathrm{day})$ than the high BF\% group $(164.3 \pm 55.6 \mathrm{~g} /$ day $)$ (Table 2). Meanwhile, there was no significant different on physical activity data among normal and high BF\% group except for total intensity variable. Mean for total intensity was higher among high BF\% group (6002.0 \pm 10137.2 MET-minute/week) than the normal group (5712.9 \pm 2885.5 MET-minute/week).

After adjusting for age and BMI (Table 3$)$, intake of protein $(\mathrm{B}=-0.018 ; \mathrm{p}=0.001)$, calcium $(B=0.001 ; p=0.010)$ and physical activity of household intensity $(B=-4.566 E-5 ; p=0.021)$ were found to be the important predictors for high $\mathrm{BF} \%$. 
Table 1. Characteristics of the studied participants [presented as mean \pm s.d. or $n(\%)$ ]

\begin{tabular}{ccccc}
\hline Items & $\begin{array}{c}\text { Normal } \\
(\mathbf{n = 8 9})\end{array}$ & $\begin{array}{c}\text { High BF\% } \\
(\mathbf{n}=\mathbf{2 3 8})\end{array}$ & $\begin{array}{c}\text { Total } \\
\mathbf{( n = 3 2 7 )}\end{array}$ & $\mathbf{P}^{\text {a }}$ Value \\
\hline Age (years) & $49.8 \pm 6.0$ & $50.6 \pm 5.5$ & $50.4 \pm 5.6$ & \\
& & Ethnic & & \\
Malay & $49(55.1)$ & $180(75.6)$ & $229(70.0)$ & $<0.001^{\mathrm{b}}$ \\
Chinese & $31(34.8)$ & $26(10.9)$ & $57(17.4)$ & \\
Indian & $9(10.1)$ & $31(13.0)$ & $40(12.2)$ & \\
"Others" & 0 & $1(0.4)$ & $1(0.3)$ &
\end{tabular}

Education level

$\begin{array}{ccccc}\text { Primary } & 6(6.7) & 18(7.6) & 24(7.3) & 0.072 \\ \text { Secondary } & 47(52.8) & 155(65.1) & 202(61.8) & \\ \text { Tertiary } & 36(40.4) & 65(27.3) & 101(30.9) & \end{array}$

Work status

$\begin{array}{ccccc}\text { Employed } & 54(60.7) & 121(50.8) & 175(53.5) & 0.072 \\ \text { Unemployed } & 35(39.3) & 117(49.2) & 152(46.5) & \end{array}$

Body composition

$\begin{array}{lllll}\text { BMI }\left(\mathrm{kg} / \mathrm{m}^{2}\right) & 21.4 \pm 2.0 & 28.5 \pm 4.1 & 26.6 \pm 4.8 & <0.001^{\mathrm{b}} \\ \text { Body fat }(\%) & 28.0 \pm 4.1 & 41.9 \pm 5.7 & 38.2 \pm 8.2 & <0.001^{\mathrm{b}}\end{array}$

${ }^{a}$ Analysis using Mann-Whitney U test or Chi-Square test.

${ }^{\mathrm{b}}$ Significant at $\mathrm{p}<0.001$.

Table 2. Physical activity and dietary intake (presented as mean \pm S.D.) of the studied participants

\begin{tabular}{ccccc}
\hline Items & $\begin{array}{c}\text { Normal } \\
(\mathbf{n = 8 9})\end{array}$ & $\begin{array}{c}\text { High BF\% } \\
(\mathbf{n = 2 3 8})\end{array}$ & $\begin{array}{c}\text { Total } \\
(\mathbf{n}=\mathbf{3 2 7})\end{array}$ & $\mathbf{P}^{\mathbf{a}}$ Value \\
\hline & Dietary intake & & \\
Energy (kcal/day) & $1544.0 \pm$ & $1502.7 \pm 404.0$ & $1513.9 \pm$ & 0.406 \\
& 387.3 & & 399.4 & \\
Carbohydrate (mg/day) & $180.7 \pm$ & $164.3 \pm 55.6$ & $168.7 \pm$ & $0.015^{\mathrm{b}}$ \\
\hline
\end{tabular}




\begin{tabular}{|c|c|c|c|c|}
\hline & 49.8 & & 54.5 & \\
\hline Protein (mg/day) & $62.9 \pm 22.6$ & $69.6 \pm 35.3$ & $67.8 \pm 32.4$ & 0.065 \\
\hline Fat (mg/day) & $63.3 \pm 22.1$ & $62.8 \pm 22.8$ & $62.9 \pm 22.6$ & 0.853 \\
\hline \multirow[t]{2}{*}{ Vitamin C (mg/day) } & $166.6 \pm$ & $166.5 \pm 137.2$ & $166.5 \pm$ & 0.630 \\
\hline & 126.7 & & 134.3 & \\
\hline Vitamin E (mg/day) & $6.1 \pm 4.1$ & $5.6 \pm 3.2$ & $5.7 \pm 3.5$ & 0.563 \\
\hline \multirow[t]{3}{*}{ Calcium (mg/day) } & $546.7 \pm$ & $512.8 \pm 293.2$ & $522.0 \pm$ & 0.573 \\
\hline & 350.6 & & 309.7 & \\
\hline & \multicolumn{2}{|c|}{ Physical activity } & & \\
\hline Commute activity & $114.6 \pm$ & $118.6 \pm 152.4$ & $117.5 \pm$ & 0.206 \\
\hline (minutes/week) & 109.1 & & 141.8 & \\
\hline Leisure activity & $143.6 \pm$ & $127.8 \pm 199.9$ & $132.1 \pm$ & 0.631 \\
\hline (minutes/week) & 188.8 & & 196.8 & \\
\hline Household activity & $1011.5 \pm$ & $1101.1 \pm$ & $1076.7 \pm$ & 0.290 \\
\hline (minutes/week) & 651.1 & 2090.7 & 1814.8 & \\
\hline Working activity & $2305.0 \pm$ & $1246.8 \pm$ & $1226.3 \pm$ & 0.151 \\
\hline (minutes/week) & 2595.6 & 1888.6 & 1735.6 & \\
\hline \multirow[t]{2}{*}{ Total activity (minutes/week) } & $5712.9 \pm$ & $2594.3 \pm$ & $2552.5 \pm$ & 0.107 \\
\hline & 2885.5 & 2703.2 & 2403.7 & \\
\hline Commute intensity & $208.8 \pm$ & $205.3 \pm 284.8$ & $206.2 \pm$ & 0.118 \\
\hline (MET-minute/week) & 213.4 & & 267.0 & \\
\hline Leisure intensity & $678.2 \pm$ & $533.7 \pm 924.8$ & $573.0 \pm$ & 0.443 \\
\hline (MET-minute/week) & 921.6 & & 924.8 & \\
\hline Household intensity & $2521.0 \pm$ & $2922.7 \pm 9669.9$ & $2813.3 \pm$ & 0.088 \\
\hline (MET-minute/week) & 1669.7 & & 8292.4 & \\
\hline Working intensity & $2305.0 \pm$ & $2340.3 \pm$ & $2330.7 \pm$ & 0.278 \\
\hline (MET-minute/week) & 2595.6 & 3754.0 & 3473.4 & \\
\hline Total intensity & $5712.9 \pm$ & $6002.0 \pm$ & $5923.3 \pm$ & $0.043^{\mathrm{b}}$ \\
\hline (MET-minute/week) & 2885.5 & 10137.2 & 8773.4 & \\
\hline
\end{tabular}

\footnotetext{
${ }^{a}$ Analysis using independent t-test or Mann-Whitney U test.
} 
${ }^{\mathrm{b}}$ Significant at $\mathrm{p}<0.05$.

Table 3. Predictors of body fat percentage $(\mathrm{BF} \%)$ of the studied participants

\begin{tabular}{ccc}
\hline Items & B & P value \\
\hline Adjusted R & 0.876 & NA \\
Constant & -8.329 & $<0.001$ \\
& Coefficients & \\
Protein & -0.018 & 0.001 \\
Calcium & 0.001 & 0.010 \\
Household intensity & $-4.566 \mathrm{E}-5$ & 0.021 \\
\hline
\end{tabular}

NA-non applicable

a significant at $\mathrm{p}<0.001$

In this study, the prevalence of high $\mathrm{BF} \%$ as assessed using [19] cut-off for women adult aged 40-59 years old was high, which affects about three quarter people of this population. This prevalence was higher as compared to obesity prevalence according to $\mathrm{BF} \%$ among Saudi adults $(60 \%, \mathrm{n}=318)$ [20], which used lower cut-off value ( $\geq 30 \%$ for women). The prevalence of overweight (37.9\%) and obesity (22.9\%) in this present study were also higher as compared to NHMS data in 2015 [8],which were reported at $30.9 \%$ and $20.6 \%$ respectively among Malaysian adult women.

The prevalence reported in this paper may represent the general prevalence of overweight, obesity and high BF\% among Malaysian adult women, as the sample comprised of major ethnic groups in Malaysia with the proportion (Malays 75.6\%, Chinese 10.9\%, Indians 13.0\% and $0.4 \%$ "others") was quite similar to the national proportion (Malays $68.6 \%$, Chinese $23.4 \%$, Indians $7 \%$ and $1.0 \%$ “others") [21]. This small scale data is very useful to generalize the prevalence of overweight, obesity and high $\mathrm{BF} \%$ among adult women across the country.However, the participants community were recruited in an urban area of the country. Thus, further study which involving larger scale of random sample from the population is suggested to provide a more precise epidemiology evidence.

For dietary data, except for protein intake, all data among high $\mathrm{BF} \%$ group showed lower mean than the normal group. Particularly, carbohydrate intake among the high BF\% group was significantly lower as compared to the normal group which suggests possible dieting 
issues among subjects in high BF\% group. According to [22], common failure in following traditional weight loss strategies among overweight and obese people has prompted a surge in alternative diet approaches like carbohydrate restriction (Atkins), fat restriction (Ornish) or replacing carbohydrate with protein (Zone). However, without proper weight loss strategy, losing weight is rather difficult to achieve. Based on previous studies, individuals with a history of dieting will gain more weight than those without a history of dieting [23]. Nevertheless, the reason for this relationship is debatable with some studies suggested dieting makes dieters more susceptible to weight gain or it is a proxy of an already-existing susceptibility toward weight gain [24-26].

This study also revealed that decreased in protein intake will contribute significantly to the increment of fat percentage. Again, the possible dieting issue which involves the alteration in other macronutrients (i.e. carbohydrate and fat) distribution may explain the reason. According to [27], dieting to lose weight is more common among women of all ages and body weight. This study also found that women who reported dieting at the study entry were heavier and gained more weight over time than did non-dieters. Basically, to maintain health, it is recommended to follow a balance diet that is low in saturated fats and high in vitamins [28-29]. Although this guideline is well-known globally, most people do not adhere to this health behaviour and many have not even contemplated adopting it [30-31].

Increased calcium intake was also found to be a significant predictor for high body fat percentage. This finding is rather conflicting with other study which reported calcium has an anti-obesity effect, in particular, increased dietary calcium would result in decreased levels of intracellular calcium, triggering increased lipolysis [32-33]. Studies also reported inverse relationships between calcium intake and $\mathrm{BF} \%$ in women [34-36].However, some studies have not supported an inverse relationship between calcium intake and body fat among women [37-39]. A review of 49 randomized control trials also reported that dairy consumption does not aid weight or fat loss [40]. However, 91.4\% of participants in this study did not achieve the recommended nutrient intake (RNI) for Malaysian which are $1000 \mathrm{mg} /$ day and $1200 \mathrm{mg} /$ day for women adults aged 40-49 years and 50-59 years respectively [41].

This study also found that one of the physical activity variable, which is the total intensity variable, was higher among high $\mathrm{BF} \%$ group as compared to normal group. Although the 
mean was slightly higher, the standard deviation value was bigger which quantifies farther amount of value dispersion among high BF\% group. Specifically, the minimum total intensity value within the high $\mathrm{BF} \%$ group was much lower (70 MET-min/week) than the normal group (496 MET-minute/week) which remarks the possibility of lower physical activity score among the participants in high $\mathrm{BF} \%$ group.

For physical activity predictor, decreased household intensity was found to be the factor for high $\mathrm{BF} \%$ among women. Our data were consistent with the evidence which indicates that depending on frequency and intensity, not only exercise, habitual physical activity-defined as all forms of body movement with energy expenditure above resting levels including household chores-can beneficially influence health parameters [42]. By doing household chores, it can reduce the time spent being sedentary and may be as important for the promotion of physical activity to prevent fat gain, simultaneously reduce obesity among women [43]. However, in this study, the magnitude of household intensity per day and guidelines which associated with $\mathrm{BF} \%$ was not investigated.

It is acknowledged that there were some limitations in the present work. This research was limited solely to the Malaysian adult women population. In addition, the involvement of Chinese and Indian subjects were low that might overestimated the prevalence among this ethnicity. Aside from that, biomarkers which are related to body weight status were not included in this research. Sensitive biomarkers such as C-reactive protein (CRP), cortisol and adinopectin should be included in future studies.

\section{CONCLUSION}

In summary, these results indicate the continuous surge of the global public health concern namely obesity. Specifically, almost three quarter proportion of adult women in Malaysia have high $\mathrm{BF} \%$ which remarks unhealthy lifestyle. In order to better screen overweight and obesity, BMI and BIA should be used in combination. It can also be concluded that this manuscript presented lifestyle related factors that can predict $\mathrm{BF} \%$ among adult women. Monitoring the prevalence of obesity is relevant for preventing health risks, especially among women. Development of preventive measures and behavioural-changing strategies are paramount to curb undesirable health related outcomes among women. 


\section{ACKNOWLEDGEMENTS}

This project was partly funded by USIM/FRGS/FPSK/32/51415 research grant, Islamic Science University of Malaysia (USIM). The authors also acknowledge the invaluable assistance of co-researchers. Many thanks are extended to the participants, fieldworkers and others involved in the data collection.

\section{REFERENCES}

[1] World Health Organization (WHO). Obesity: Preventing and managing the global epidemic. WHO Technical Report Series, 894, Geneva: WHO, 2000

[2] Rush E C, Goedecke J H, Jennings C, Micklesfield L, Dugas L, Lambert E V, Plank L D. BMI, fat and muscle differences in urban women of five ethnicities from two countries. International Journal of Obesity, 2007, 31(8):1232-1239

[3] Razak F, Anand S S, Shannon H, Vuksan V, Davis B, Jacobs R, Teo K K, McQueen M, Yusuf S. Defining obesity cut points in a multiethnic population. Circulation, 2007, 115(16):2111-2118

[4] Kagawa M, Kerr D, Uchida H, Binns C W. Differences in the relationship between BMI and percentage body fat between Japanese and Australian-Caucasian young men. British Journal of Nutrition, 2006, 95(5):1002-1007

[5] Hung S P, Chen C Y, Guo F R, Chang C I, Jan C F. Combine body mass index and body fat percentage measures to improve the accuracy of obesity screening in young adults. Obesity Research and Clinical Practice, 2017, 11(1):11-18

[6] Fernández J R, Heo M, Heymsfield S B, Pierson R N, Pi-Sunyer F X, Wang Z M, Wang J, Hayes M, Allison D B, Gallagher D. Is percentage body fat differentially related to body mass index in Hispanic Americans, African Americans, and European Americans? American Journal of Clinical Nutrition, 2003, 77(1):71-75

[7] Romero-Corral A, Somers V K, Sierra-Johnson J, Korenfeld Y, Boarin S, Korinek J, Jensen M D, Parati G, Lopez-Jimenez F. Normal weight obesity: A risk factor for cardiometabolicdysregulation and cardiovascular mortality. European Heart Journal, 2009, 31(6):737-746 
[8] Institute for Public Health. National and health morbidity survey 2015. Putrajaya: Ministry of Health Malaysia, 2015

[9] World Health Organization (WHO). Obesity: Preventing and managing the global epidemic. Report of a WHO Consultation on Obesity. Geneva: WHO, 1998

[10] Kulie T, Slattengren A, Redmer J, Counts H, Eglash A, Schrager S. Obesity and women's health: An evidence-based review. Journal of the American Board of Family Medicine, 2011, 24(1):75-85

[11] Patterson R E, Frank L L, Kristal A R, White E. A comprehensive examination of health conditions associated with obesity in older adults. American Journal of Preventive Medicine, 2004, 27(5):385-390

[12] Practice Committee of the American Society for Reproductive Medicine. Obesity and reproduction: An educational bulletin. Fertility and Sterility, 2008, 90(5):21-29

[13] Shah M B. Obesity and sexuality in women. Obstetrics and Gynecology Clinics of North America, 2009, 36(2):347-360

[14] Kaaks R, Lukanova A, Kurzer M S. Obesity, endogenous hormones, and endometrial cancer risk. Cancer Epidemiology and Prevention Biomarkers, 2002, 11(12):1531-1543

[15] Willett W C. Is dietary fat a major determinant of body fat? American Journal of Clinical Nutrition, 1998, 67(3):556S-562S

[16] Carruth B R, Skinner J D. The role of dietary calcium and other nutrients in moderating body fat in preschool children. International Journal of Obesity, 2001, 25(4):559-566

[17] Reiner Z, Catapano A L, De Backer G, Graham I, Taskinen M R, Wiklund O, Agewall S, Alegria E, Chapman M J, Durrington P, Erdine S. The task force for the management of dyslipidaemias of the European Society of Cardiology (ESC) and the European Atherosclerosis Society (EAS): ESC/EAS Guidelines for the management of dyslipidaemias. European Heart Journal, 2011, 32(14):1769-1818

[18] Irwin M L, Yasui Y, Ulrich C M, Bowen D, Rudolph R E, Schwartz R S, Yukawa M, Aiello E, Potter J D, McTiernan A. Effect of exercise on total and intra-abdominal body fat in postmenopausal women: A randomized controlled trial. Journal of American Medical Association, 2003, 289(3):323-330 
[19] Gallagher D, Heymsfield S B, Heo M, Jebb S A, Murgatroyd P R, Sakamoto Y. Healthy percentage body fat ranges: An approach for developing guidelines based on body mass index. American Journal of Clinical Nutrition, 2000, 72(3):694-701

[20] Habib S S. Body mass index and body fat percentage in assessment of obesity prevalence in Saudi adults. Biomedical and Environmental Sciences, 2013, 26(2):94-99

[21] Department of Statistics Malaysia (DOSM). Anggaranpenduduksemasa, Malaysia 2014-2016. Putrajaya: DOSM, 2016

[22] Alhassan S, Kim S, Bersamin A, King A C, Gardner C D. Dietary adherence and weight loss success among overweight women: results from the A TO Z weight loss study. International Journal of Obesity, 2008, 32(6):985-991

[23] Lowe M R, Shank L M, Mikorski R, Butryn M L. Personal history of dieting and family history of obesity are unrelated: Implications for understanding weight gain proneness. Eating Behaviors, 2015, 17:144-148

[24] Neumark-Sztainer D, Wall M, Haines J, Story M, Eisenberg M E. Why does dieting predict weight gain in adolescents? Findings from project EAT-II: A 5-year longitudinal study. Journal of the American Dietetic Association, 2007, 107(3):448-455

[25] Houben K, Nederkoorn C, Jansen A. Too tempting to resist? Past success at weight control rather than dietary restraint determines exposure-induced disinhibited eating. Appetite, 2012, 59(2):550-555

[26] Lowe M R, Levine A S. Eating motives and the controversy over dieting: Eating less than needed versus less than wanted. Obesity, 2005, 13(5):797-806

[27] Savage J S, Hoffman L, Birch L L. Dieting, restraint, and disinhibition predict women's weight change over 6 y. American Journal of Clinical Nutrition, 2009, 90(1):33-40

[28] Hu F B, Willett W C. Optimal diets for prevention of coronary heart disease. Journal of American Medical Association, 2002, 288(20):2569-2578

[29] World Health Organization (WHO). Diet, nutrition, and the prevention of chronic diseases. World Health Organization Technical Reports Series 916, Geneva: WHO, 2003 [30] Jackson C, Lawton R, Knapp P, Raynor D K, Conner M, Lowe C, Closs S J. Beyond intention: Do specific plans increase health behaviours in patients in primary care? A study of fruit and vegetable consumption. Social Science and Medicine, 2005, 60(10):2383-2391 
[31] Riebe D, Greene G W, Ruggiero L, Stillwell K M, Blissmer B, Nigg C R, Caldwell M. Evaluation of a healthy-lifestyle approach to weight management. Preventive Medicine, 2003, $36(1): 45-54$

[32] Zemel M B. Regulation of adiposity and obesity risk by dietary calcium: Mechanisms and implications. Journal of the American College of Nutrition, 2002, 21(2):146S-151S [33] Zemel M B. Mechanisms of dairy modulation of adiposity. Journal of Nutrition, 2003, 133(1):252S-256S

[34] Eilat-Adar S, Xu J, Loria C, Mattil C, Goldbourt U, Howard B V, Resnick H E. Dietary calcium is associated with body mass index and body fat in American Indians. Journal of Nutrition, 2007, 137(8):1955-1960

[35] Beydoun M A, Gary T L, Caballero B H, Lawrence R S, Cheskin L J, Wang Y. Ethnic differences in dairy and related nutrient consumption among US adults and their association with obesity, central obesity, and the metabolic syndrome. American Journal of Clinical Nutrition, 2008, 87(6):1914-1925

[36] Boon N, Koppes L L, Saris W H, Van Mechelen W. The relation between calcium intake and body composition in a Dutch population: The Amsterdam growth and health longitudinal study. American Journal of Epidemiology, 2005, 162(1):27-32

[37] Murakami K, Okubo H, Sasaki S. No relation between intakes of calcium and dairy products and body mass index in Japanese women aged 18 to 20 y. Nutrition, 2006, 22(5):490-495

[38] Poddar K H, Hosig K W, Nickols-Richardson S M, Anderson E S, Herbert W G, Duncan S E. Low-fat dairy intake and body weight and composition changes in college students. Journal of the American Dietetic Association, 2009, 109(8):1433-1438

[39] Reynolds J C, Sebring N G, McHugh T. Effects of calcium supplementation on body weight and adiposity in overweight and obese adults. Annals of Internal Medicine, 2009, 150:821-829

[40] Lanou A J, Barnard N D. Dairy and weight loss hypothesis: An evaluation of the clinical trials. Nutrition Reviews, 2008, 66(5):272-279

[41] National Coordinating Commitee of Food and Nutrition (NCCFN). Recommended nutrient intakes for Malaysian. Putrajaya: Ministry of Health, 2017 
[42] Bembom O, van der Laan M, Haight T, Tager I. Leisure-time physical activity and all-cause mortality in an elderly cohort. Epidemiology, 2009, 20(3):424-430

[43] Scheers T, Philippaerts R, Lefevre J. Objectively-determined intensity-and domain-specific physical activity and sedentary behavior in relation to percent body fat. Clinical Nutrition, 2013, 32(6):999-1006

[44] Shahar S, Earland J, Suriah A R. Validation of a dietary history questionnaire against a 7-D weighed record for estimating nutrient intake among rural elderly Malays. Malaysian Journal of Nutrition, 2000, 6(1):33-44

[45] Wendel-Vos G W, Schuit A J, Saris W H, Kromhout D. Reproducibility and relative validity of the short questionnaire to assess health-enhancing physical activity. Journal of Clinical Epidemiology, 2003, 56(12):1163-1169

\section{How to cite this article:}

Johari S M, Nordin N J, Sahar M A, Sulaiman A H, Shahar S, Teng N I M F, Amin N A, Saudi A S M. High body fat percentage among adult women in malaysia: the role of lifestyle. J. Fundam. Appl. Sci., 2017, 9(4S), 905-919. 